\title{
Correction to: Application of Nanotechnology in Agricultural Farm Animals
}

Naresh L. Selokar, Seema Dua, Dharmendra Kumar, Bharti Sharma, and Monika Saini

\section{Correction to: \\ Chapter 1 in: M. Ghorbanpour et al. (eds.), Biogenic Nano-Particles and their Use in Agro-ecosystems, https://doi.org/10.1007/978-981-15-2985-6_1}

The original version of the chapter was inadvertently published with an incorrect reference citation.

Page 4, 3rd line from bottom, the reference was cited with forenames of the authors as (Damian and Konrad 2018) but it should be cited with surnames as (Konkol and Wojnarowski 2018).

The citation and the corresponding reference have been updated with this erratum.

The updated online version of this chapter can be found at https://doi.org/10.1007/978-981-15-2985-6_1 